\title{
Distanciamento físico e ensino remoto: socializações em tempos de pandemia
}

\author{
Physical distance and remote learning: socializations in times of pandemic
}

\author{
Distanciamiento físico y educación remota: socializaciones en tiempos de pandemia
}

\author{
Paula Alexandra Reis Bueno* \\ Roberto Eduardo Bueno ${ }^{* *}$
}

\section{Resumo}

Objetivou-se capturar e analisar marcas de socializações advindas do ensino remoto, durante o fechamento das instituições de educação formal, em virtude da pandemia da Covid-19. Primeiramente, desenvolveu-se uma análise documental, a partir de ensaios de organizações não governamentais (ONGs), pareceres de Conselhos de Educação, relatórios de pesquisas e documentos complementares. Visando verificar variações intrapessoais, realizaram-se entrevistas com 57 sujeitos, entre estudantes e professores da educação básica e mestrandos e doutorandos de um programa de pós-graduação. Encontrou-se um panorama dividido em posicionamentos e valores; o fortalecimento de instâncias socializadoras em universos virtuais; novas maneiras, formas e técnicas de se ensinar e aprender; e disposições para uma educação mesclada entre o ensino presencial e o ensino remoto, com construções de novas formas de se ensinar, estudar, aprender e se relacionar entre humanos. Menções sobre processos adaptativos, dificuldade de concentração e dificuldade de aprender sem o acompanhamento presencial de um professor figuraram entre os relatos mais recorrentes. Espera-se contribuir para o campo da sociologia e da educação, no sentido de apoiar os estudos que verificam as contínuas construções e reconstruções das formas de se agir e pensar.

Palavras-chave: socialização; educação; tecnologias de informação e comunicação; ensino a distância; Covid-19.

\section{Abstract}

The objective of this study was to capture and analyze socialization marks from remote education, during the closing of formal education institutions, due to the Covid-19 pandemic. First, a documentary analysis was developed, based on essays by non-governmental organizations (NGOs), opinions from Education Councils, research reports and complementary documents. In an attempt to verify intrapersonal variations, interviews were carried out with 57 subjects, including students and teachers of Basic Education, and masters and doctoral students of the same university program. It was found a panorama divided into positions and values; and strengthening socializing instances in virtual universes; also new ways, forms and techniques of teaching and learning; and dispositions for an education blended between face-to-face and remote education, with constructions of new

\footnotetext{
Recebido: 30/07/2020 - Aprovado: 15/04/2021

http://dx.doi.org/10.5335/rep.v28i1.11480
}

Doutora em Educação pela Faculdade de Educação da Universidade de São Paulo (FE-USP) e mestre em Educação pela Universidade Federal do Paraná (UFPR). Atua como professora da educação básica vinculada à SEED/PR. Atuou como professora de pós-graduação do IBPEX e CENSUPEG. Pesquisadora vinculada à USP e à UFPR. Orcid: http:// orcid.org/0000-0002-4595-513X. E-mail: paula.reis.musica@gmail.com

** Pós-doutorado, doutor, mestre e especialista em Saúde Coletiva pela Pontifícia Universidade Católica do Paraná (PUCPR). Professor do Bacharelado em Saúde Coletiva e dos Programas de Pós-graduação em Políticas Públicas, Ensino das Ciências Ambientais e Desenvolvimento Territorial Sustentável da Universidade Federal do Paraná (UFPR). Pesquisador vinculado à USP e à UFPR. Orcid: http://orcid.org/0000-0001-5546-8397. E-mail: roberto.edu.bueno@gmail.com 
ways of teaching, studying, learning and relating among humans. Mentions about adaptive processes, difficulty concentrating and difficulty learning without the presence of a teacher in person, were among the most recurrent reports. It is expected to contribute to the field of sociology and education, in order to support studies that verify the continuous constructions and reconstructions of the ways of acting and thinking.

Keywords: socialization; education; information and communication technologies; distance learning; Covid-19.

\title{
Resumen
}

\begin{abstract}
El objetivo fue capturar y analizar las marcas de socialización de la educación remota, durante el cierre de las instituciones de educación formal, debido a la pandemia Covid-19. En primer lugar, se desarrolló un análisis documental, basado en ensayos de organizaciones no gubernamentales (ONG), opiniones de Consejos de Educación, informes de investigación y documentos complementarios. Con el fin de verificar variaciones intrapersonales, se realizaron entrevistas a 57 sujetos, entre estudiantes y docentes de Educación Básica, y estudiantes de maestría y doctorado de un Programa de Posgrado. Se encontró un panorama dividido en posiciones y valores; fortalecer instancias de socialización en universos virtuales; nuevas formas, formas y técnicas de enseñanza y aprendizaje; y disposiciones para una educación combinada entre la educación presencial y a distancia, con la construcción de nuevas formas de enseñar, estudiar, aprender y relacionarse entre los humanos. Las menciones sobre procesos adaptativos, dificultad para concentrarse y dificultad para aprender sin la supervisión presencial de un docente, se encuentran entre los informes más recurrentes. Se espera contribuir al campo de la sociología y la educación, para sustentar estudios que verifiquen las continuas construcciones y reconstrucciones de las formas de actuar y pensar.
\end{abstract}

Palabras clave: socialización; educación; tecnologías de la información y la comunicación; la educación a distancia; Covid-19.

O ser humano nasce em contextos sociais próprios, que os apresentam formas de agir e pensar. Socializa-se em suas relações com o mundo, com os outros e consigo mesmo. Constrói-se ao longo de sua existência, a partir de suas experiências e escolhas. Esse texto busca refletir sobre esse processo de socialização, em tempos de distanciamento físico, em virtude da pandemia da Covid-19. Como se dão as relações intrapessoais, com instituições e demais sujeitos em momentos de mudanças nas relações sociais advindas de um distanciamento físico? Em especial, como se dá a relação ensino e aprendizagem na perspectiva da educação formal?

O conceito de socialização vem sendo utilizado por diversos estudiosos do campo da sociologia, assim como do campo da educação. Setton e Bozzetto (2020), com o apoio de Berthelot (1983), afirmam que a análise dos processos de socialização demanda o olhar para as instituições, assim como para a história e experiências de vida dos indivíduos, seus valores pessoais e grupais, e o contexto socio-histórico em que estão imersos. Desta maneira, tal conceito abrange um potencial de interpretação das representações e reproduções sociais em diversas dimensões socioculturais, permitindo a observação de como se constituem as compreensões e visões de mundo. 
Em Durkheim (1978), a ideia de socialização se concretizava com a integração social, num processo de adaptação ao meio e condições sociais impostas ao indivíduo por estruturas sociais como família, escola, igreja, entre outras. Entretanto, a compreensão contemporânea do conceito propõe pensar uma ação dialética e interdependente entre estas estruturas sociais e as estruturas mentais de cada sujeito.

As relações com instituições sociais contribuem para a compreensão e reprodução do mundo vivido, para a incorporação de disposições de habitus pelos indivíduos, como diria Bourdieu (2001). Mas, na contemporaneidade, os indivíduos estão submetidos a uma pluralidade de instâncias socializadoras (LAHIRE, 2006), podendo estar simultaneamente e sucessivamente em diversos mundos sociais não homogêneos e, por vezes, contraditórios (SETTON, 2016).

Desta forma, os sujeitos se encontram expostos às disposições de habitus não homogêneas e consequentemente há diferentes orientações para suas práticas, com construções de caráter pessoal, maneiras próprias de ser e estar no mundo, promovidas por uma dinâmica de híbridas combinações e escolhas, que Setton (2012) irá denominar de "disposições híbridas de habitus".

A partir dessa perspectiva do conceito de socialização, torna-se possível a análise de processos de individuação e construções de identidades, individuais e de grupos, por meio de relações indissociáveis entre indivíduos e estruturas sociais; de mecanismos de resistência e disputa, de permanências e rupturas, ou seja, trata-se de um entendimento dialógico e multidimensional do conceito, quando o indivíduo encontra-se com autonomia de escolhas, reflexividade e participação na construção de si (SETTON; BOZZETTO, 2020).

Outra característica dessa abordagem contemporânea do conceito de socialização é o entendimento que a identidade não é fixa, o habitus não é estático, mas clivado, construído ao longo da vida (BOURDIEU; CHARTIER, 2012; DUBAR, 2005; BERGER; LUCKMANN, 2014). Para Dubar (2005), existem sucessivas socializações numa existência humana, permitindo diversas construções, desconstruções e reconstruções de identidades ligadas às muitas esferas de atividade e às mudanças sociais. Bourdieu esclarece seu entendimento de que "o habitus não é um destino... trata-se de um sistema aberto de disposições que está submetido constantemente a experiência e, desse modo, transformado por essas experiências" (BOURDIEU; CHARTIER, 2012, p. 62).

O conceito de socialização abrange, também, algumas especificidades, como o papel do pertencimento, da linguagem e do reconhecimento nesse processo. Para Berger e Luckmann (2014), se a socialização consiste na compreensão do mundo, 
ela acontece por meio da linguagem, ou seja, o desenvolvimento da linguagem permite que os indivíduos objetivem seu mundo exterior, uma vez que a linguagem propicia o adentrar num universo simbólico e cultural. Os autores escrevem a partir dos estudos de Mead (1968), que, por sua vez, apresenta como a última etapa do processo de socialização, o indivíduo ser reconhecido pelo seu grupo. Dubar (2005) realiza a leitura de Berger e Luckmann enfatizando que a socialização apresenta uma dupla dimensão: de construir a si mesmo e obter um reconhecimento recíproco, ou seja, ser reconhecido por quem se reconhece. Com a leitura dos textos de Hegel, Dubar encontra o entendimento de que o reconhecimento recíproco é o ápice da socialização, e a linguagem evidencia esse reconhecimento (HEGEL apud DUBAR, 2005).

Bourdieu (2013) empreende esforços e desvela mecanismos ocultos para o reconhecimento em um campo específico de seu espaço social, no caso, a academia. Os achados do sociólogo parecem ainda válidos para o referido campo social, mesmo na realidade brasileira; ou seja, a estrutura do espaço dos poderes, numa academia, envolve notoriedade intelectual, poder científico, acúmulo de posições que permitem controlar outras, notoriedade da instituição de pertença, entre outras classificações. Ainda, para além do espaço do Ensino Superior, elementos dessa estrutura do espaço de poder, também podem ser encontrados em outras instituições, como nas escolas de Educação Básica, por exemplo.

No entanto, outro espaço se impõe na sociedade contemporânea, no qual o reconhecimento parece ser advindo de views e likes. Refere-se ao espaço virtual, que em 2020 ganhou ainda mais força, devido à necessidade de um distanciamento social, que se nomeará neste estudo de distanciamento físico, ocorrido por conta de uma pandemia viral que assolou a vida e as experiências. Optou-se pela nomeação "distanciamento físico", pois no universo da internet, as relações sociais se intensificaram, ocorrendo muitas lives (transmissões ao vivo), cursos e vídeos diversos postados em mídias sociais e outros meios digitais.

Diante desse contexto se questiona se os espaços de poderes do mundo virtual imitam o do mundo material, ou se transformam nessa realidade paralela? Em que medida esses dois mundos se intersectam e se influenciam nesta segunda década do século XXI? Como isso se reflete nas socializações e consequentemente nas formas de se agir e pensar? Como se dão as relações intrapessoais, com instituições e sujeitos em momentos de distanciamento físico? Em especial, como se dá a relação ensino e aprendizagem na perspectiva da educação formal? 
Esses inquietantes e amplos questionamentos emergiram quando dois professores pesquisadores mudaram suas rotinas de trabalho de salas físicas e olhos nos olhos, para salas virtuais e olhos na tela. Refletindo sobre as questões abordadas, voltaram-se aos documentos de instâncias que interviram na dinâmica das aulas remotas.

Os Conselhos de Educação orientaram para o andamento da educação formal durante o período de distanciamento físico. Muitas de suas orientações foram contempladas nas resoluções das Secretarias de Educação. Esses conselhos, por sua vez, são representados por indivíduos da sociedade civil, mas, também, recebem pressão política das ONGs; sendo que nem sempre essas instituições apresentaram posicionamentos convergentes. Duas ONGs se manifestaram de forma bastante expressiva quanto ao ensino remoto, e alcançaram maior visibilidade.

Desta forma, visando promover a reflexão, buscou-se uma análise em documentos publicados por essas ONGs; pelos Conselhos de Educação; relatórios de pesquisa sobre o tema; e documentos oficiais de uma Secretaria de Educação, de uma Universidade Federal e de um Sindicato. As escolhas desses últimos documentos complementares se deram em virtude do recorte do estudo, que se efetivou a partir dos estabelecimentos de trabalho dos pesquisadores, e na perspectiva de uma segunda abordagem, realizada a partir da análise de falas de indivíduos envolvidos no ensino remoto durante a pandemia da Covid-19.

Desta forma, posteriormente, voltou-se para professores e estudantes de duas realidades institucionais distintas, no Estado do Paraná, região sul do Brasil, para uma investigação empírica dos efeitos do ensino remoto em suas socializações.

\section{Desenvolvimento metodológico}

A primeira etapa do estudo contou com uma análise documental, a partir de documentos publicados, conforme apresentados no Quadro 1: 
Quadro 1 - Relação dos documentos analisados

\begin{tabular}{|c|c|}
\hline Tipo e origem & Título \\
\hline $\begin{array}{l}\text { Ensaios de ONGs: } \\
\text { Campanha Nacional pelo Direito à Edu- } \\
\text { cação (CNDE) }\end{array}$ & $\begin{array}{l}8 \text { motivos para não substituir a educação presencial pela educa- } \\
\text { ção a distância }(\mathrm{EaD}) \text { durante a pandemia }\end{array}$ \\
\hline Todos pela Educação & $\begin{array}{l}\text { Nota técnica: Ensino a distância na educação básica frente à pan- } \\
\text { demia da Covid-19 }\end{array}$ \\
\hline $\begin{array}{l}\text { Pareceres de Conselhos de Educação: } \\
\text { Conselho Nacional de Educação (CNE) }\end{array}$ & $\begin{array}{l}\text { PARECER CNE/CP №: } 11 / 2020 \text { - Orientações Educacionais para } \\
\text { a Realização de Aulas e Atividades Pedagógicas Presenciais e } \\
\text { Não Presenciais no contexto da Pandemia. }\end{array}$ \\
\hline $\begin{array}{l}\text { Conselho Estadual de Educação do Pa- } \\
\text { raná (CEE) }\end{array}$ & $\begin{array}{l}\text { Deliberação CEE/CP №: } 01 / 2020 \text {, de } 31 \text { de março de } 2020 \text {. Insti- } \\
\text { tuição de regime especial para o desenvolvimento das atividades } \\
\text { escolares no âmbito do Sistema Estadual de Ensino do Paraná } \\
\text { em decorrência da legislação específica sobre a pandemia cau- } \\
\text { sada pelo Novo Coronavírus - Covid-19 e outras providências. }\end{array}$ \\
\hline $\begin{array}{l}\text { Relatórios de Pesquisas: } \\
\text { Universidade Federal do Paraná (UFPR) }\end{array}$ & $\begin{array}{l}\text { O que pensam crianças e familiares das aulas remotas: notas pre- } \\
\text { liminares da pesquisa }\end{array}$ \\
\hline Fundação Carlos Chagas (FCC) & Educação escolar em tempos de pandemia \\
\hline $\begin{array}{l}\text { Documentos Complementares: } \\
\text { Universidade Federal do Paraná (UFPR) }\end{array}$ & $\begin{array}{l}\text { RESOLUÇÃO № 59/2020-CEPE - Regulamenta, em caráter ex- } \\
\text { cepcional, período especial para o desenvolvimento de atividades } \\
\text { de ensino nos cursos de educação superior, profissional e tecno- } \\
\text { lógica da UFPR, no contexto das medidas de enfrentamento da } \\
\text { pandemia de Covid-19 no país. }\end{array}$ \\
\hline $\begin{array}{l}\text { Secretaria da Educação e do Esporte do } \\
\text { Estado do Paraná (SEED/PR) }\end{array}$ & $\begin{array}{l}\text { Institucional: Educação desenvolve EaD com foco no protagonis- } \\
\text { mo dos professores }\end{array}$ \\
\hline $\begin{array}{l}\text { Sindicato dos Trabalhadores em Educa- } \\
\text { ção Pública do Paraná (APP Sindicato) }\end{array}$ & $\begin{array}{l}\text { Manifesto por uma educação humanizadora e em defesa da vida: } \\
\text { Contra as políticas educacionais de produção de exclusão e desi- } \\
\text { gualdades em tempo de pandemia de Covid- } 19\end{array}$ \\
\hline
\end{tabular}

Fonte: elaboração dos autores, 2020.

Para a referida análise utilizou-se o software Atlas.ti 8. Primeiramente, após a leitura dos textos, buscou-se capturar grupos de temas emergentes. Nesse sentido, na primeira etapa, foi possível agrupar códigos temáticos, organizados em quatro grupos distintos, os quais: Grupo 1: Aspectos gerais do texto: a) Objetivos; b) Abrangência; Grupo 2: Resultados apresentados: c) Atividades desenvolvidas; d) Dificuldades; e) Êxitos; f) Porcentagem de participação ou acesso; Grupo 3: Achados: g) Dados de pesquisa; h) Posicionamentos e discursos de indivíduos e grupos; i) Desigualdades; Grupo 4: Características: j) Observações, aspectos e dimensões das decisões; k) Possibilidades e direcionamentos; e l) Dimensão política. 
Após esse estudo nos documentos, percebeu-se a necessidade de se voltar para os indivíduos, e compreender melhor os efeitos desse ensino remoto, no contexto específico em análise, ou seja, como os sujeitos percebiam mudanças, rupturas ou permanências, nas formas de se ensinar, de estudar e aprender, relacionadas às socializações vinculadas à educação formal, diante do referido momento socio-histórico.

Nesse sentido, devido à prática docente dos pesquisadores, optou-se pela utilização dos mediadores tecnológicos para acesso aos indivíduos em interação, ou seja, por um lado, foram convidados 277 estudantes e 28 professores da Educação Básica, vinculados a Escola Estadual Prof. Abigail dos Santos Correa, situada em Matinhos, no litoral Paranaense; e 18 mestrandos e doutorandos, matriculados na disciplina "Análise de Políticas Públicas", do Programa de Pós-Graduação em Políticas Públicas da Universidade Federal do Paraná (UFPR), com sede em Curitiba, capital do Estado do Paraná. Na somatória dos três grupos, 57 indivíduos responderam ao inquérito. As respostas foram submetidas ao mesmo tratamento analítico que os documentos, ou seja, se agrupou por blocos temáticos. ${ }^{1}$

Ademais, voltou-se novamente aos textos, e as falas dos entrevistados, na perspectiva de verificar a possibilidade de fazer uso das quatro categorias analíticas apresentadas por Lahire (2015), e retomadas em Setton e Bozzetto (2020) e, observando também, as categorias Berthelot (1983), também elencadas pelas autoras.

Para Berthelot (1983), conforme mencionado anteriormente, uma análise sociológica precisa considerar as instituições; as experiências de vida dos agentes; seus valores pessoais e grupais; e o contexto socio-histórico, ou seja, a história em que estão imersos. Assim, instituições, agentes, valores e história constituem as quatro categorias analíticas sugeridas por Berthelot.

Para Lahire (2015), a análise sociológica deveria considerar as categorias: quadros (universo, instâncias, instituições); modalidades (maneiras e formas de agir); efeitos (disposições de agir, sentir e pensar); e tempo (momento de um percurso individual). Desta forma, as quatro categorias sugeridas pelo autor são: quadros, modalidades, efeitos e tempo.

Considerando o referencial teórico, denominou-se a primeira categoria analítica, no presente estudo, de "panorama", na perspectiva de retomar a categoria "tempo" do Lahire e "história" de Berthelot; ou seja, os documentos e falas foram novamente analisados no sentido de perceber o panorama da educação formal durante a pandemia da Covid-19, buscando entender o momento dos percursos dos 
indivíduos, e as características das ações socializadoras, quanto ao seu tempo de duração, grau de intensidade e ritmo.

Na segunda categoria analítica, em analogia às "modalidades" do Lahire e aos "agentes" do Berthelot, buscou-se perceber os "posicionamentos" dos indivíduos e grupos diante da educação remota disponibilizada, considerando as experiências de vida, anteriores e durante o ensino e aprendizagem em questão, assim como os modos e formas de agir.

$\mathrm{Na}$ terceira categoria analítica, baseou-se em "instituições" do Berthelot e "quadros" do Lahire, na perspectiva de verificar a potência das estruturas nos processos socializadores durante o ensino remoto. Essa categoria foi nomeada de "vozes", na busca de desvendar exercícios de poder advindos das instâncias, e verificar como as ações tomadas impactaram os percursos individuais no contexto histórico vivenciado.

$\mathrm{Na}$ última categoria analítica, voltou-se para os "valores" do Berthelor e os "efeitos" do Lahire, na perspectiva de capturar disposições de habitus incorporadas e em mutações, ou seja, em rupturas e construções. Essa categoria ficou nomeada como "implicações", a fim de capturar e descrever os resultados das socializações investigadas.

Desta forma, efetivou-se a análise dos textos a partir dos quatro grupos de categorias, alinhando-as em rede de códigos nas quatro novas categorias centrais da presente análise, combinando-as com a análise das falas, também alinhadas às referidas categorias. Assim, intencionou-se verificar como os documentos respondiam e apresentavam o panorama da educação formal na pandemia da Covid-19, como ressoavam as vozes das instituições, os posicionamentos dos indivíduos e grupos, seus valores e ações, no intuito de perceber indícios de processos socializadores, com implicações nas disposições de habitus.

\section{0 panorama da educação formal diante da pandemia da Covid-19 no Brasil}

Em dezembro de 2019, a China é surpreendida por um surto de infecção por SARS-CoV-2, pertencente à família de vírus denominada coronavírus. Rapidamente a infecção vai se espalhando pelo planeta e em 11 de março de 2020, a Organização Mundial da Saúde declarou o surto de uma pandemia, tendo atribuído como nome oficial Covid-19 (OPAS/OMS BRASIL, 2020).

No Brasil, o primeiro caso de contágio pelo novo coronavírus foi confirmado em 25 de fevereiro de 2020, no Estado de São Paulo, em um indivíduo que havia 
retornado de uma viagem à Itália. Em 10 de março de 2020 é confirmado o primeiro caso no Estado do Paraná. Sendo que em 05 de março o Ministério da Saúde já havia confirmado transmissão local em São Paulo. Desde então, o Brasil foi desenvolvendo um panorama crítico de contágio, chegando à marca de 13.373.174 casos confirmados acumulados em 09 de abril de 2021, com 348.718 óbitos acumulados (BRASIL, 2021).

A pandemia da Covid-19 impactou a educação formal e seus sistemas educacionais em todo o mundo, fechando portas de estabelecimentos físicos e ampliando o contato via meios virtuais. Dados encontrados nos documentos analisados, afirmam que entre março e junho de 2020, 56,3 milhões de estudantes, entre Educação Básica e Ensino Superior, estiveram fora das salas de aula no Brasil (BRASIL, 2020b).

O histórico apresentado pelo Conselho Nacional de Educação (CNE), via Ministério da Educação (MEC), na "Proposta de parecer sobre reorganização dos calendários escolares e realização de atividades pedagógicas não presenciais durante o período de pandemia da Covid-19”, consta da seguinte ordem de fatos:

No dia 17 de março de 2020, por meio da Portaria nº343, o Ministério da Educação (MEC) se manifestou sobre a substituição das aulas presenciais por aulas em meios digitais, enquanto durar a situação de pandemia da COVID-19 (...) Em 18 de março de 2020, o Conselho Nacional de Educação (CNE) veio a público elucidar aos sistemas e às redes de ensino, de todos os níveis, etapas e modalidades, considerando a necessidade de reorganizar as atividades acadêmicas (...) Conselhos Estaduais de Educação de diversos estados e vários Conselhos Municipais de Educação emitiram resoluções e/ou pareceres orientativos para as instituições de ensino pertencentes aos seus respectivos sistemas sobre a reorganização do calendário escolar e uso de atividades não presenciais. Em 20 de março de 2020, o Congresso Nacional aprovou o Decreto Legislativo no 6 que reconhece, para os fins do artigo 65 da Lei Complementar no 101 , de 4 de maio de 2000, a ocorrência do estado de calamidade pública... (BRASIL, 2020a, não paginado).

A análise documental realizada verificou um panorama com divergências de opiniões quanto à manutenção dos calendários escolares e acadêmicos. $\mathrm{O}$ ponto unificador foi a concordância com a necessidade do distanciamento físico e fechamento de escolas e universidades.

Considerando a realidade dos outros países e as orientações da Organização Mundial de Saúde e seus cientistas vinculados, os textos reconheceram a importância de medidas de distanciamento físico, focadas em atrasar o contágio, para mitigar os efeitos na sociedade e sistemas de saúde. Desta forma, o fechamento das instituições de ensino se tornou eminente, no sentido de representar um ponto im- 
portante para o então chamado "achatamento da curva epidemiológica" (WORLD HEALTH ORGANIZATION, 2020), a fim de prevenir o colapso nos serviços de saúde e dar tempo hábil para o surgimento e aplicação de vacinas e tratamentos.

Os aspetos gerais dos textos objetivaram, por um lado, orientar e normatizar o ensino remoto, assim como o retorno às aulas presenciais, quando autorizado pelas autoridades de saúde. Por outro lado, alguns textos objetivaram argumentar sobre os motivos de não se utilizar do ensino remoto, especialmente sem um amplo diálogo com a comunidade escolar, e por meios virtuais, devido, especialmente, às desigualdades sociais e de acesso.

Dos nove textos analisados, sete apresentaram ampla abrangência de participação para sua produção escrita e na produção de dados. E, todos se posicionam como direcionados a um público que engloba: a comunidade escolar e famílias, profissionais da educação e proteção da criança e adolescente, assim como ao poder público em esferas federativas.

As atividades desenvolvidas compuseram: a) aulas ao vivo e gravadas por professores, e transmitidas em meios digitais (YouTube, Google Classroom e mídias sociais) e TV aberta; b) comunicação via rádio; c) interações com estudantes em plataformas digitais, chats, mensagens e reuniões (Meets), compreendendo desde orientações genéricas, até tutorias; d) produção e disponibilização de materiais digitais via $W e b$ e materiais impressos produzidos por professores e entregues pelas escolas.

As principais dificuldades se relacionaram ao acesso a esses meios digitais, ou por falta de equipamentos; falta de um bom acesso à internet; da capacidade de utilização dos recursos disponíveis; da logística da casa e das condições da família. Também, foram observadas dificuldades relacionadas à disciplina e à organização do tempo e espaço de estudo, no sentido de ter um local adequado e a necessidade de atendimento dos responsáveis às demandas dos estudantes.

Apareceram nos documentos descritos, êxitos na ampliação da relação família-escola, e do vínculo do estudante com a sua família. Quanto à porcentagem de participação nas aulas remotas, o texto do CNE estimou que 74\% dos estudantes brasileiros participaram de alguma atividade não presencial, numa variação de 94\% de participação dos estudantes da região sul para 52\% de participação dos estudantes na região norte do país (BRASIL, 2020b).

Todos os textos apresentaram desigualdades relacionadas ao capital econômico, que refletiram em desigualdade de acesso, de disponibilidade de equipamentos, de ambientes adequados para o estudo. Também, de capital cultural: um dos 
textos apresentou, como dado de pesquisa, a influência direta da escolaridade dos responsáveis no sucesso do estudante, no formato de aulas remotas. Diante desta realidade, por um lado, grupos defenderam em seus documentos um posicionamento contrário ao recurso do ensino remoto durante a crise da pandemia. Um grupo se posicionou contra a educação remota no formato proposto pelo governo do seu Estado, e outro por qualquer modalidade de EaD para a Educação Básica; em ambos os casos, os principais argumentos se relacionaram a exclusão, coação, descumprimento do princípio de gestão democrática e precarização.

Do lado dos que defenderam a educação remota, um dos textos afirmou que o panorama não permitia comparar "aulas a distância" com "aulas presenciais", pois a questão fundamental é "aulas a distância" e "não realização de aulas", e nesse sentido, apresentaram dados de países que interromperam o funcionamento de escolas por longos períodos (por situações de guerra, desastres naturais, entre outros motivos) argumentando que a "escolha do poder público em nada fazer, sob o argumento de que não é possível "chegar a todos", tende a exacerbar as desigualdades resultantes da situação de emergência” (TODOS PELA EDUCAÇÃO, 2020).

Contudo, todos os textos afirmaram que o formato de educação remota, sugerido para o período, não substituiria as aulas presenciais, sendo que, por um lado, a situação foi entendida como um ato antidemocrático, e por outro, como uma medida para amenizar danos. Todos os textos elencaram, no entanto, o temor da possibilidade de evasões e reprovações em grandes proporções.

Os textos apresentaram posicionamentos políticos em defesa da necessidade de maiores investimentos em educação, e de mudanças em suas concepções, salientando, por um lado, a necessidade de maior inclusão das classes sociais menos favorecidas de forma equitativa e democrática, dando poder de voz aos sujeitos, e por outro lado, da compreensão da importância dos aspectos socioemocionais da educação, do estreitamento de vínculos, e da qualidade do ensino formal.

A análise dos textos permitiu vislumbrar mudanças significativas na educação formal, e nas disposições de agir de seus sujeitos, advindas da pandemia da Covid-19. Descrições da necessidade de adequação ou reescrita de ementas e currículos, da necessidade de abordagens metodológicas diferenciadas e da possibilidade de maior hibridação do ensino presencial e remoto, com utilização de meios digitais, figuraram nos documentos.

A leitura dos textos motivou para compreender um pouco mais como os indivíduos sentiram esse momento de seu percurso individual e como perceberam o grau de intensidade e ritmo das ações. Para observar o panorama na dimensão dos su- 
jeitos, realizaram-se inquéritos individualizados, conforme apresentados na sessão anterior. A observação à escala dos indivíduos confirmou um panorama polarizado, contendo favoráveis e contrários ao ensino remoto na educação formal, no entanto, com a compreensão de que o universo digital se tornou uma ferramenta ainda mais expressiva ao ensino regular.

Os comentários sobre as atividades desenvolvidas e as dificuldades assemelharam-se às expostas nos textos. Porém, nas falas se apresentou, com maior intensidade, a dimensão do afeto. $\mathrm{Na}$ fala de estudantes, assim como de professores da Educação Básica, foram frequentes os relatos de que a experiência, da educação formal na pandemia, preveria uma maior aproximação nas relações interpessoais no retorno as aulas presenciais, devido ao estabelecimento da percepção da importância do contato e das trocas. Para os doutorando e mestrando, as falas também mencionam trocas entre pares, fundamentais para o processo de aprofundamento nos estudos e para as reflexões; e nesse sentido, o referido grupo de respondentes, mencionou a importância da aproximação via plataformas digitais, que permitiram, mesmo com limitações, a troca de ideias e sentidos de leituras e estudos. O tema é retomado na apresentação dos resultados da categoria implicações.

Portanto, o panorama da educação formal no período da pandemia da Covid-19, apresentou-se como desafiador, como um momento de crise, com ideias divergentes e percursos individuais intensos, de grandes transformações sendo impostas em curtos períodos de tempo.

\section{Vozes socializadoras}

Nesta categoria analítica, buscou-se descrever e analisar o conjunto das instâncias socializadoras relacionadas à educação formal no contexto da pandemia da Covid-19. Suas diversas vozes, ou seja, a potência das estruturas no universo do ensino/aprendizagem.

Entende-se que as instâncias socializadoras da educação formal, por excelência, são as instituições de ensino, ou seja, escolas, colégios, universidades, etc. Que atuam por meio dos sujeitos da educação: professores, estudantes, diretores, pedagogos, agentes. No entanto, essas instituições de ensino estiveram submetidas à influência e ao poder de outras instâncias, como as secretarias de educação, por exemplo, que normatizaram o processo de ensino. Ainda, essas secretarias tomaram decisões forjadas por outras instâncias, como os Conselhos de Educação, a pressão política das ONGs e movimentos da sociedade civil. 
Desta forma, para se compreender os quadros e instituições, que exerceram poder socializador, nessa dinâmica da educação formal durante o primeiro período da pandemia de Covid-19 no Brasil, fez-se necessário ouvir as diversas vozes que reverberaram no ensino remoto.

Uma parte dos discursos desses grupos já foram apresentados na categoria supracitada, quando se mencionou o panorama fragmentado e crítico da educação formal. Nesse momento, busca-se, no entanto, esclarecer a composição dessas instituições, complementar o discurso e apresentar um olhar para outra voz que ressoou nesse contexto.

$\mathrm{Na}$ análise documental, sete textos foram escritos com ampla abrangência de participação para sua produção. Dentre eles, encontram-se dois escritos por Conselhos de Educação; dois textos de uma universidade federal, com envolvimento de diversos professores/pesquisadores, e 158 famílias entrevistadas em um deles; um texto escrito por uma fundação de direito privado sem fins lucrativos, e com uma das áreas de atuação a Pesquisa Educacional, tendo 14.285 docentes respondentes da pesquisa; e dois textos escritos por ONGs formadas por indivíduos de diversos segmentos.

O primeiro texto, apresentado no Quadro 1, é de origem da ONG "Campanha Nacional pelo Direito à Educação (Campanha)”, que, em sua plataforma digital, afirma ser composta de um conjunto de organizações da sociedade civil, que participaram Cúpula Mundial de Educação em Dakar (Senegal), no ano 2000, e tem como objetivo somar diferentes forças políticas, visando mobilização social, "pressão política e comunicação social, em favor da defesa e promoção dos direitos educacionais" (CAMPANHA..., 2020). A ONG declara que é fundadora da Campanha Global pela Educação (CGE), pela Campanha Latino-Americana pelo Direito à Educação (Clade) e Rede Lusófona pelo Direito à Educação (ReLus).

O segundo texto, apresentado no Quadro 1, é de origem da ONG "Todos pela Educação", a qual se considera "suprapartidária e independente", afirma não receber recursos públicos e ter como missão contribuir para melhorar a Educação Básica no Brasil. A ONG considera sua articulação ampla e plural, pois afirma compreender centenas de grupos e entidades, incluindo comunidades escolares, movimentos sociais, sindicatos, ONGs nacionais e internacionais, grupos universitários, estudantis e outros cidadãos da sociedade civil. É mantida e apoiada por empresas privadas, e realiza pesquisas e atuações em diversas frentes, como na elaboração do atual PNE, por exemplo (TODOS PELA EDUCAÇÃO, 2020). 
O texto do CNE afirma ter sido escrito com a participação de entidades nacionais como a União Nacional dos Dirigentes Municipais de Educação (Undime), o Conselho Nacional de Secretários de Educação (Consed), a União Nacional dos Conselhos Municipais de Educação (UNCME), a FNCEM, o Fórum das Entidades Educacionais (FNE), além da interlocução com especialistas e entidades da sociedade civil.

O texto do CEE não especifica as instituições representadas, apenas menciona que foram 18 instituições, e ao final do documento há uma "declaração de voto contrário à deliberação" em questão, emitida pela APP Sindicato, revelando uma das instituições participantes.

Os dois textos que não esclareceram a dimensão da participação, de indivíduos e/ou grupos, para a produção da escrita, se compuseram de: um texto que apresenta a proposta e forma de efetivação das aulas remotas, da Secretaria de Educação e Esporte do Estado do Paraná e; um texto que se opõe a proposta de aulas remotas em ambientes virtuais de aprendizagem, escrito pelo Sindicato dos Trabalhadores em Educação Pública do Paraná (APP Sindicato).

Desta forma, é possível aferir que os discursos, presentes nos textos, emergem de importantes instituições vinculadas a educação, órgãos públicos, universidades, pesquisadores, estabelecimentos de educação, sociedade civil e movimentos sociais.

Todos os textos apresentaram importantes pontos de reflexão, com resultados de pesquisas, sensos e análises sociais, mas com defesa de posicionamentos situados, ou seja, formas distintas de se pensar a educação transpareceram na leitura do material. Por um lado, o pensamento da qualidade na educação por meio do alcance de parâmetros internacionalmente balizados, com desenvolvimento de autonomia e tecnologia no processo de ensino. Por outro lado, o discurso da educação como prática humanizadora, includente, comunicativa e reflexiva, que preza pelo respeito à diversidade, à equidade e à participação social.

Acreditou-se, portanto, que o indivíduo, na sua construção pessoal, pode aderir, mais facilmente, aos discursos vinculados às suas instituições de pertença, ao pensamento hegemônico em suas teias de relações, o que não excluiu a possibilidade de práticas reflexivas e rupturas.

No entanto, observou-se nos documentos e falas, que os indivíduos, diante do panorama já apresentado, acabaram expostos a mais uma instância socializadora em sua educação formal: o universo virtual, que invadiu o tempo do ensino e da aprendizagem. Pois, se por um lado, de um momento para outro, todos estavam diante de plataformas digitais de ensino e aprendizagem, para seu processo formal 
de educação. Por outro lado, esse momento da educação formal era atravessado por mensagens de WhatsApp, vídeos de YouTube, figurinhas e "memes" diversos que foram formatando formas de se agir e pensar durante o processo.

As mídias há muito tempo vêm socializando os indivíduos, essa já era uma preocupação dos estudiosos da Escola de Frankfurt. Setton (2012, p. 146) acreditou que o estudante brasileiro se socializa "com base na interdependência entre sistemas de referências híbridos, forjados pelas instâncias tradicionais da educação, e também em sistema difuso de conhecimento e informações veiculados pelas mídias". Em suas pesquisas, a autora (2012, p. 151) identificou que os estudantes se utilizavam das mídias tanto como mediadores de um saber difuso e pré-científico, quanto como sistematizadores de conhecimentos escolares. Concordando com as observações da autora, salienta-se que os celulares já estavam tão presentes, mesmo no cotidiano das escolas, que se fez necessário a criação de uma lei proibindo seu uso durante as aulas, a Lei n.․ 2.246-A/2007 (BRASIL, 2009).

No entanto, era comum o uso dos meios digitais, pelos jovens, de uma maneira lúdica, espontânea e intuitiva. Eles selecionavam os conteúdos do seu interesse, interagiam e trocavam fotos, vídeos e mensagens. Com o advento das aulas remotas foi como se a escola invadisse as telas. Aulas expositivas, carregadas de conteúdos, com longas durações, precisaram ser acessadas, seguidas de atividades para serem resolvidas nesse ambiente virtual. Muitas horas de exposição às telas, com pouca interação com colegas e professores. Essa foi uma realidade na Educação Básica do Estado do Paraná, no primeiro semestre de 2020, conforme os relatos das entrevistas e dados de pesquisa dos documentos. $\mathrm{E}$ isso aconteceu, mesmo com a presença de alertas, em todos os textos analisados, da necessidade de adequação da linguagem para esses meios. Mas, como não se pode "jogar o bebê junto com a água do banho", a utilização de algumas ferramentas, como o Google Classroom e as plataformas de Meet, por exemplo, serviu para a alfabetização em uma linguagem que há muito se impõe à educação, a linguagem do mundo virtual.

Sintetizando, a referida categoria temática evidenciou que as instituições de ensino formal, enquanto instâncias socializadoras, receberam influências de outras instâncias, vinculadas ao poder público e à sociedade civil organizada, que impactaram em suas formas de socialização, formatando novas práticas e percepções acerca do ensino e da aprendizagem.

Corroborando com estudos anteriores, como o de Setton (2012), foi aferido o impacto das Tecnologias Digitais de Informação e Comunicação nas formas de se ensinar e aprender. E ampliando o olhar para além da dimensão da educação 
formal, visualizando abrangentemente as maneiras como os indivíduos se relacionaram com o universo virtual, e como essas relações têm formatado formas de agir, sentir e pensar, se considerou os meios digitais como importantes instâncias socializadoras da contemporaneidade.

\section{Posicionamentos de indivíduos e grupos}

Nessa dimensão analítica, buscou-se capturar os modos de agir e as experiências dos indivíduos e grupos, numa busca de estudar a maneira pela qual se organizou e se desenvolveu os processos socializadores.

O posicionamento da ONG "Campanha" foi contrário ao ensino remoto, pois percebeu um despreparo, em termos estruturais e formativos, dos estabelecimentos e sujeitos da educação, para essa forma de ensino e aprendizagem. Também, considerou os excluídos digitais que, conforme seu documento, configuravam mais da metade da população brasileira. A "Campanha" entendeu que não pode ser exigido, dos estudantes da Educação Básica, a autonomia, capacidade de concentração e autodisciplina que essa forma de ensino requer. Ainda, que o ensino remoto complexificaria a gestão das redes, com diversos calendários, ações de formação e avaliação das unidades. Para a ONG, até o Ensino Superior poderia apresentar estudantes abandonando os cursos frente às dificuldades encontradas com o ensino remoto. E, finalizou sua argumentação, alertando para os oportunismos das empresas de tecnologias e de comunicação, para o risco de apropriação de dados, e privatizações.

A ONG “Todos pela Educação" acreditou que, devido ao panorama imposto pela pandemia, o ensino remoto se constituiria como uma alternativa, podendo contribuir e devendo ser implantado. Admitiu, no entanto, que seus efeitos eram limitados, e por isso a importância de sua normatização e seu planejamento de retorno. Compreendeu a necessidade do entendimento das diferenças de disposição de recursos tecnológicos e desigualdade entre os sujeitos, estando ciente de que os indivíduos com melhores desempenhos acadêmicos tendem a se beneficiar mais das soluções tecnológicas. E alertou para a diferenciação entre ensino remoto e aula online, incentivando a diversidade de experiências de aprendizagem significativas, na crença de que essas experiências podem apoiar a criação de rotinas positivas, com certa estabilidade frente ao momento de mudanças. Por fim, a ONG salientou o papel do professor como central no processo de ensino remoto.

Os pareceres dos CNE e CEE orientaram e normatizaram a educação e as atividades não presenciais, prezando pela liberdade de ensinar, aprender, pesquisar, 
e divulgar o pensamento, a arte e o saber; a valorização dos profissionais da educação; igualdade de condições de acesso e permanência; e a garantia de um padrão de qualidade no ensino. Para isso, apresentou diversas orientações de ordem prática e bastante específicas. Com a observação da realidade vivenciada pelos demais países, e de pesquisas que já foram publicadas, os pareceres alertaram para condições de crise na educação, sendo necessários investimentos de todos os setores, tanto na dimensão estrutural e financeira, quanto: nas adaptações de calendários e currículos; na clareza e no enfrentamento à possibilidade de evasão, com abertura a processos de ensino e aprendizagem socioemocionais; fortalecimento da gestão democrática, comunicativa e participativa; e a busca dos melhores patamares possíveis de aprendizado, orientado a necessidade de retomadas e adequações no currículo para o ano de 2021.

A Resolução no 59-2020-CEPE da UFPR regulamentou o período especial para o desenvolvimento de atividades de ensino em seus cursos de educação superior, profissional e tecnológica, no contexto da pandemia da Covid-19 no Brasil. Com característica democrática, o documento descentralizou as decisões, ao regulamentar a oferta do período especial para o $1^{\circ}$ semestre letivo de 2020. No artigo $4^{\circ}$, autorizou os colegiados dos cursos a decidirem e procederem com a oferta de novas turmas de disciplinas e unidades curriculares; ficando também a critério das coordenações de curso solicitar apoio à Superintendência de Inclusão, Políticas Afirmativas e Diversidade para o acompanhamento de estudantes surdos/surdas e com deficiências, de modo a assegurar a plena inclusão nas disciplinas ou unidades curriculares ofertadas de forma remota. Nas disposições gerais, estabeleceu no artigo 28 que a oferta de disciplinas e unidades curriculares no período especial era de caráter totalmente voluntário para as unidades administravas e ao corpo docente da UFPR, reafirmando o princípio de que o direito à vida se sobrepõe a todos os demais. Finalizou, no artigo 31, afirmando que caberia à administração central e às unidades conexas (pró-reitorias e órgãos suplementares) da UFPR manterem ações com vistas à inclusão e ao letramento digital, assim como à expansão do uso de tecnologias digitais nas atividades de ensino-aprendizagem, para o ensino remoto emergencial nos cursos de educação superior, profissional e tecnológica da UFPR (UFPR, 2020).

Todavia, o texto institucional da SEED/PR apresentou à comunidade uma proposta pronta, na qual viabilizou a compreensão das ações pontuais, visando à oferta de educação durante o período da pandemia da Covid-19. O governo estadual incluiu aulas em canais abertos de TV, no YouTube e outros aplicativos; a 
oferta de pacotes gratuitos de dados de internet para aqueles que acessaram via um aplicativo chamado Aula Paraná, desenvolvido especialmente para esse período; e utilização da plataforma Google Classroom, para a disposição de atividades e interação entre estudantes, e destes com os professores. No texto, os professores da rede são denominados de "protagonistas" da proposta do governo, uma vez que coube a eles a gravação das aulas, assim como de elaboração de atividades e formas de interação com os estudantes.

Em contraposição à proposta da SEED/PR, a APP Sindicato criticou a orientação política da referida secretaria que estaria visando a "obtenção de resultados educacionais quantitativos", medidos através de avaliações externas aos estabelecimentos de ensino, com "intensificação do processo de controle e coação sobre os(as) profissionais da educação". Denunciou que novas orientações eram encaminhadas rotineiramente, causando instabilidade, e "agindo como instrumentos de tutela, controle, vigilância e punição sobre o trabalho pedagógico", isso estaria esgotando a autonomia dos sujeitos e comunidades escolares em definirem seus processos de ensino e aprendizagem. $\mathrm{O}$ documento declarou que em nenhum momento houve um diálogo com a comunidade escolar sobre os encaminhamentos para a efetivação do ensino remoto (APP SINDICATO, 2020).

Os dois relatórios de pesquisa apresentaram as maneiras, formas e técnicas utilizadas nas abordagens investigadas de ensino remoto. A pesquisa realizada pela FCC teve abordagem em todas as 27 Unidades da Federação, com participação de 14.285 docentes da Educação Básica, especialmente de escolas públicas e urbanas. Os sujeitos de pesquisa declararam que a rotina de trabalho envolveu: a) escrever e responder e-mail, WhatsApp e SMS; b) planejar e preparar aulas com novas ferramentas; c) ministrar aulas com novos recursos; d) assistir e participar de cursos, lives e reuniões; e) apoio às famílias de estudantes. As estratégias educacionais envolveram trabalho com as mídias sociais, tanto para comunicação, quanto para a elaboração e envio de trabalhos. Ademais, o texto mencionou: a) a utilização de materiais disponibilizados pelas secretarias de educação, em formatos digitais ou impressos para serem retirados na escola; b) aulas online ao vivo ou gravadas; e c) comunicações via rádio.

O relatório da pesquisa realizada pela UFPR, reuniu relatos de 150 famílias residentes no Litoral do Paraná e na Região Metropolitana de Curitiba, com contato via WhatsApp, e-mail, telefonemas e interações de campo. Somando-se a essas, encontram-se "relatos de trabalhadores sociais de instituições e serviços de proteção, cujos dados indiretos referem-se a oito famílias em condição de acompanha- 
mento socioassistencial" (THOMASSIM; HOFFMANN-HOROCHOVSKI, 2020, p. 1). O estudo apontou diferenças entre as percepções do ensino remoto em relação aos estudantes das escolas públicas e privadas, sendo que os estudantes das escolas privadas, além de terem maiores condições estruturais de acesso, sentiram-se menos sobrecarregados de atividades, o texto afirmou que foram recorrentes as reclamações dos pacotes de videoaulas das escolas públicas estaduais, que mantiveram os sujeitos em maior tempo de exposição às telas. $\mathrm{O}$ estudo explicou que a rede estadual do Paraná seguiu a lógica de cinco videoaulas de 50 minutos ao dia, e mais as atividades a serem desenvolvidas nas plataformas digitais. As famílias relataram a dificuldade de os estudantes manterem a concentração em toda a aula, pois, com celulares em mãos, eles tendiam a se distraírem com jogos, vídeos e mensagens de colegas. Outros dados apresentados pela pesquisa salientam a necessidade de organização do tempo e dinâmica familiar, além da reorganização de espaços, divisão de aparelhos, fez-se importante o apoio dos familiares aos estudantes. $\mathrm{O}$ estudo apresentou, como considerações finais, a fragilidade do modelo de ensino remoto, em que foram submetidos os sujeitos de pesquisa, no sentido de garantir experiências educacionais significativas, relevantes e democráticas.

De maneira semelhante, nas falas dos entrevistados para o presente estudo, os estudantes mencionaram a dificuldade de adaptação à rotina de aulas remotas, o tempo diante das telas, a quantidade de atividades, a facilidade de dispersão devido ao contexto espacial da casa e também do universo virtual, com notificações e chamadas competindo com as explicações dos professores. Ademais, a dificuldade apresentada com maior recorrência nas falas dos entrevistados, foi a de aprender sem o acompanhamento presencial dos professores:

Maria $(\mathrm{EB})^{2}$ - Bom, nós conseguimos aprender nas aulas online, mas na minha opinião as aulas presenciais são melhores, porque os professores podem ver a dificuldade de cada um e ajudar, e eu acho que na sala de aula a gente consegue aprender melhor.

João (EB) - Porque estamos acostumados com o jeito dos professores explicarem, e é mais difícil entender o que os professores das aulas online falam.

Pedro (EB) - Eu acho que esse tipo de ensinamento mudou a maneira de aprendermos, pois somente assistimos, não tem como tirarmos dúvidas e nem conversarmos com colegas.

De fato, os professores relataram que estiveram presentes nas mídias durantes as aulas, e em interação pelo WhatsApp e demais aplicativos, como o Google Classroom. No entanto, existiu uma necessidade de apropriação da forma de se 
estabelecer um relacionamento entre professores e estudantes nesse meio digital, como elaborar as questões, como enviá-las, sendo que a aula gravada não tem interrupção para o estudante processar tais reflexões, e como o tempo de gravação é muito expandido, o estudante se focou em finalizar as atividades e concluir o procedimento de cada aula que foi bastante exaustivo. Desta forma, as atividades desenvolvidas e dificuldades apresentadas, nesse grupo analítico, corroboraram para a compreensão da necessidade do desenvolvimento de uma linguagem específica para o ensino remoto, tanto para facilitar as relações entre os sujeitos da educação, como na elaboração técnicas de atividades concatenadas com o formato de ensino e aprendizagem nestes ambientes não presenciais.

Desta forma, os posicionamentos de indivíduos e grupos, por um lado, foram de argumentações favoráveis ou contrárias ao ensino remoto durante o distanciamento físico imposto pela pandemia; também de orientação, regulamentação e monitoramento de ações.

Por outro lado, a ação prática de ensinar e aprender num outro formato, que envolveu disciplina, autonomia, independência, controle emocional e arranjo nos espaços físicos domésticos e nas rotinas diárias, o que exigiu alterações nos relacionamentos intrafamiliares, e mudanças de percepções do papel e importância docente.

\section{As implicações do ensino remoto na pandemia da Covid-19}

Nessa categoria analítica, se buscou os efeitos do ensino remoto nas formas de agir e pensar dos agentes, ou seja, em suas socializações; nas palavras de Lahire (2015, p. 1395), em suas disposições a acreditar, sentir, julgar, representar, agir.

Nos documentos analisados, são apresentados dados, de pesquisas realizadas, no exterior e também no Brasil, que demonstraram algumas implicações da pandemia da Covid-19 e do ensino remoto, nos agentes e sistemas de educação formal. Para os objetivos desta análise, elencaram-se apenas alguns, relacionados às realidades brasileira e paranaense.

$\mathrm{Na}$ pesquisa da FCC, as(os) docentes perceberam um processo de aprendizagem acontecendo, pela produção e execução das atividades, que atingiu cerca de $50 \%$ dos estudantes. Os respondentes, em maioria, afirmaram que o ensino remoto promoveu o aumento tanto da relação escola-família, quanto do vínculo do estudante com sua família. Também, um fortalecimento do vínculo dos profissionais de um mesmo estabelecimento de ensino, uma vez que precisaram se apoiar 
mutuamente e contar com o apoio dos gestores. Ajornada de trabalho foi ampliada para os profissionais investigados e, em alguns casos, o salário foi reduzido. Os investigados acreditaram que, os prenúncios de possíveis mudanças na educação formal, estariam no ensino online ocorrendo juntamente com o presencial. Ao desenvolverem uma maneira de ensinar mediados pelo universo digital, os professores incorporaram disposições didáticas, que podem (ou não) ser duradouras. $\mathrm{O}$ texto expõe conforme apresentado a seguir:

De fato, a situação imposta pela pandemia exigiu, de um lado, repensar os conteúdos e atividades avaliativas, considerando a diversidade de situações e condições de vida em que se encontram os estudantes dos diversos níveis de ensino. Não se trata, apenas, de transpor práticas que antes eram feitas presencialmente para contextos virtuais (FCC, 2020, p. 3).

Nas falas dos docentes da Educação Básica, respondentes do presente estudo, esse achado também aparece como um efeito socializador:

Joana $(P)$ - Acredito que esse período vem trazer uma nova era no campo educacional. Foram muitas descobertas sobre novas formas de ensino e aprendizagem. Nunca mais vou lecionar da mesma forma. Inclusive esse período me incentivou a continuar lecionando.

Marília (P) - Penso que vai mudar muito a prática de todos. Mesmo antes de tudo isso, nós já usávamos muitas mídias na educação, mas nunca de forma tão intensa. Muita coisa foi imposta e nós nos adaptamos. Aperfeiçoamo-nos e até incrementamos muitas coisas. Quanto tudo voltar ao novo normal eu acredito que muito do que estamos usando agora irá continuar.

Eduardo $(P)$ - Afeta pelo fato de que aprendi muita coisa com essa ferramenta. Sei que poderei usar isso depois, mesmo dando aulas presenciais. Acho que dá para fazer muita coisa boa se bem utilizada. Prefiro a aula presencial, mas como estamos nesse momento horroroso acho que foi bom, até me surpreendi (...) o fato é saber aproveitar a oportunidade! Quem faz o mínimo com a ferramenta faz o mesmo nas aulas presenciais, eu vou aprendendo e dando o melhor de mim!

José (P) - Então, eu penso que vai afetar sim! Não tem como voltar a ser como era antes, então penso que teremos que nos adaptar e que tudo isso será positivo para professores e estudante; os estudantes sendo mais autônomos e livres para buscar novos conhecimentos, a questão da responsabilidade e nós estaremos nos reinventando, aprendendo e fazendo parte desse universo todo!

São muitos os relatos como esses, que enfatizaram a continuidade da utilização dos meios digitais para o ensino, mesmo depois do retorno às aulas presenciais. Relatos que confirmaram a efetivação de novas formas de agir e pensar na própria prática docente. 
De maneira bem menos expressiva, encontraram-se falas de docentes, que apresentaram a possibilidade dessas disposições serem transitórias, e de não se constituírem uma socialização permanente no ensino formal e nas práticas didático pedagógicas:

Marta (P) - Confesso que não gosto da forma como está afetando minha atividade docente (...) acredito que descobrimos uma ferramenta, mas valorizo muito mais o que obtemos no contato direto com os estudantes (...) não vislumbro seu uso fora dessa realidade.

Tiago (P) - Diante da precariedade de acesso de nossos alunos, não acredito que possa utilizar na volta às aulas.

E duas falas docentes, deixaram uma dúvida sobre a potência dessa disposição para o uso das tecnologias, surgidas a partir da realidade do ensino remoto:

Janete $(P)$ - Agora, se irá afetar positiva ou negativamente não sei responder. É evidente que se fosse uma questão de democracia, onde todos tivessem o acesso, seria muito positiva a inclusão de uma plataforma de ensino remoto, como uma complementação da carga horária e para estudo do que foi visto na escola. Porém, não como uma substituição como está ocorrendo.

Cristina $(P)$ - Isso vai refletir na nossa vida e práticas! Não sei de que forma, mas certamente deixará marcas! Certamente continuaremos a utilizar a ferramenta, mas também estamos traumatizadas com ela.

Lahire (2015) alertou que, as pesquisas já realizadas, atestaram que não é interessante negligenciar o poder de reorientação ou modificação das disposições de habitus incorporadas anteriormente a um evento, assim como, não é interessante negligenciar a capacidade da produção de novas disposições mentais, que transformam maneiras de se agir e pensar.

Nas falas dos estudantes da educação básica, assim como de alguns professores, emergiu a dimensão do afeto nos processos de ensino e de aprendizagem. Muitos estudantes afirmaram ter outra percepção da figura do docente, entendendo seu papel e a falta que faz os atendimentos individualizados e personalizados, efetivados no cotidiano da sala de aula, para o aprendizado dos conteúdos escolares e das características dos relacionamentos humanos. De maneira simples, os estudantes e professores elencaram o lugar do afeto nas construções de identidades. A seguir, três exemplos de falas de discentes e um exemplo de fala de docente, respectivamente: 
Brenda (EB) - Nada substitui um professor em sala de aula, o convívio com os colegas e a rotina escolar.

Bruno (EB) - No ensino à distância você não tem um professor para você perguntar (...) e nem para ficar brigado por causa da postura dele.

Caio (EB) - De forma alguma substitui as aulas presenciais, porque a escola é essencial como espaço de socialização e de aprendizado e a presença do professor nem se fala, no dia a dia ele percebe o aluno que conseguiu aprender, aquele que tem dificuldades e o que fazer para poder ajudar.

Tiago (P) - Com toda certeza, após a pandemia, não seremos os mesmos, nem nossas aulas serão! Vai afetar justamente o afeto, o amor será maior ainda, o afeto, acolhimento!

Essa dimensão do afeto tem sido trabalhada pela teoria da socialização, na perspectiva de sua importância para os aspectos socializadores. (SIMMEL, 2001; BERGER; LUCKMANN, 2014; DUBAR, 2005; SETTON, 2013; BUENO; BUENO, 2019). No presente estudo, as falas promoveram a retomada dessa teoria para enfatizar como as emoções participam da incorporação de disposições para determinadas aprendizagens. Simmel (2001, p. 162) se referiu ao afeto como um "aglutinante social", que composto nas experiências, apresenta função formativa da vida psíquica. Simmel (2001, p. 149), inspirado em Platão, entendeu o amor como uma força necessária ao percurso para o conhecimento, e o pontuou como um potencializador de ideias.

Voltando-se às respostas das entrevistas de mestrandos e doutorandos, eles confirmaram o entendimento de que o modelo remoto exige processos de estudo e aprendizagem mais autônoma, assim como dificulta a interação, especialmente entre pares, tornando o estudo e aprendizado mais solitário, com menos interações e, portanto, com menos trocas de ideias promotoras de insights. Porém, os entrevistados consideraram o ensino remoto uma importante alternativa, para a pós-graduação.

Rodrigo (PG) - A forma de aprender se torna mais autônoma. Na falta de contato com os demais colegas e professores, nos aprofundamos solitariamente no programa das disciplinas. Talvez o prejuízo maior seja a perda do dinamismo e da diversidade de ideias e informações que normalmente surgem durante as aulas presenciais. Contudo, há de se considerar que esse prejuízo foi bastante reduzido devido às estratégias e sensibilidade dos professores, que se esforçaram bastante para tornar o ambiente o mais produtivo e acessível para todos. Em relação ao distanciamento interpessoal que esse momento impôs a todos, embora tenha prejudicado as interações e o intercâmbio de ideias entre colegas, também foi amenizado com grupos de WhatsApp onde todos puderam interagir. Claro, cada qual do seu modo, mas sempre de forma respeitosa, democrática e construtivamente. 


\section{Foi elencado como um ponto positivo a questão de não se perder tempo com deslocamentos.}

Teresa (PG) - Há aspectos positivos: como o aproveitamento do tempo que seria perdido em deslocamentos e maior flexibilidade para a execução das atividades, considerando quem trabalha e estuda. Se eu estivesse na rotina habitual, certamente estaria muito estressada tentando conciliar tudo.

Salienta-se um ponto já tratado, mas evidenciando que em todas as modalidades de entrevistados, foi mencionada a dificuldade de manter a concentração nas aulas virtuais, principalmente no formato expositivo, ou seja, para aulas em plataformas digitais faz-se necessário pensar em abordagens dinâmicas e interativas. E, essa dificuldade não é mencionada apenas por jovens estudantes, mas também ficou marcada nos documentos analisados, e na fala de uma doutoranda e de um professor da Educação Básica, que se expressaram conforme pontuado a seguir:

Melissa (PG) - Senti uma perda da qualidade de retenção do conteúdo, já que cada aula concentra muitos seminários e é muito difícil prestar atenção com concentração em frente ao computador por várias horas e com as demandas de trabalho interrompendo há todo momento (...) a interação é reduzida, com mais dificuldade de elaboração de perguntas, apesar de todo esforço por parte dos professores. Eu preferiria poder ouvir mais explanações dos professores aliadas as nossas leituras prévias.

Maurício $(\mathrm{P})$ - Acredito que esse modelo de aula será uma mera lembrança quando as aulas retornarem fisicamente, o formato ficou ruim, muito difícil um estudante se concentrar por tanto tempo.

Jairo (EB) - Acho ruim. Não gosto e não consigo prestar atenção! Queria que voltassem as aulas presenciais.

A última fala a ser mencionada reforça como a organização do tempo e do espaço interfere no aprendizado, quando se estuda em casa. Também, demonstra o surgimento de novas disposições de habitus relacionados à educação formal e à construção da identidade, quando o respondente afirma que no início não gostava de trabalhar em casa, mas agora gosta:

Henrique (PG) - Apresentei baixa produtividade nos primeiros 35 dias de trabalho remoto. Após esse período, já acostumado com a nova rotina em casa e com novo espaço físico, usado especialmente para esse fim, tudo ficou mais fácil. Trabalhar no quarto era muito complicado, as rotinas se misturam e a qualidade de vida decai muito. Horários bagunçados, não sentia prazer nem em estar no quarto para dormir, pois inconscientemente sabia que ao acordar ali mesmo já teria uma enxurrada de afazeres. Mas após a mudança de ambiente tudo mudou, e confesso, agora estou gostando do home office. 


\section{Esperanças e perspectivas: considerações finais}

Desde a etapa de coletas de informações e análises do presente estudo, que aconteceram no primeiro semestre de 2020, o panorama da educação formal e da pandemia da Covid-19 passou por transformações, as quais nem sempre foram positivas. Até o início de abril de 2021, apesar de algumas iniciativas e aberturas temporárias, de modo geral, as escolas mantiveram-se fechadas; no entanto, mais adaptadas ao modelo remoto. A UFPR encontrava-se em organização para a retomada oficial do calendário acadêmico, mais uma vez com aulas remotas.

A vacinação teve início no país em fevereiro de 2021, porém com implementação lenta das aplicações. Todavia, essa ação mobilizou esperanças e perspectivas de um retorno à "normalidade" dos contatos físicos e da vida em sociedade. Mas permaneceu o questionamento do que seria essa normalidade, quando se mencionavam um "novo normal" numa sociedade marcada pelo advento dramático e perturbador de uma pandemia.

Corroborando com estudos anteriores, a presente pesquisa demonstrou que o panorama histórico e temporal das sociedades, interfere nas formas de socialização. A pandemia da Covid-19 gerou novas práticas e percepções acerca do ensino e aprendizado. Como essas práticas impactaram as disposições de habitus, aferiu-se um indicativo para maior envolvimento com o universo tecnológico e digital, desenvolvendo uma linguagem própria, o idioma das redes. Essa linguagem, de aparência globalizada, exige maiores estudos dos pesquisadores a fim de se compreender suas limitações e abrangências. Salienta-se a importância de constantes reflexões e críticas aos produtos culturais e como eles podem implicar em disposições de habitus em construções e transformações.

No panorama da educação formal, as mídias digitais se colocaram de forma proeminente, com seus softwares e universos da Web. No Brasil, e mais especificamente, no Estado do Paraná, há muito se fala das inclusões das Tecnologias Digitais de Informação e Comunicação na educação formal. Apesar das diversas ações implantadas nos últimos anos, como a instalação de TVs Pendrives nas salas de aulas, disponibilização de tablets para professores, criação de laboratórios de informática em alguns estabelecimentos de ensino, Registro de Classe On-line, entre outras ações nas instituições e realidades escolares... todas essas ações pouco alteraram as práticas pedagógicas e formas de se ensinar e aprender.

$\mathrm{O}$ advento da pandemia da Covid-19, contudo, trouxe uma mudança significativa nesse contexto, com o relacionamento entre os sujeitos da educação, quase 
exclusivo ou exclusivamente, pelas plataformas digitais. Professores e estudantes precisaram se adaptar à nova realidade de atividades remotas e às formas expressivas de utilização de tecnologias voltadas ao ensino e à aprendizagem. Podendo (ou não) se constituírem em efeitos duradouros, pois se referem às socializações ocorridas em curto espaço temporal. Os estudos de Lahire e Bourdieu detalham sobre os processos de disposições de habitus acontecendo ao longo de trajetórias de vida. No entanto, considerando como as mídias têm impactado as formas de ser, agir e pensar nas últimas décadas, acredita-se que novas disposições para o ensino e o aprendizado estão sendo consolidadas.

Verificou-se pela análise dos documentos, a possibilidade de ampliação de desigualdades sociais no Brasil advindas da situação imposta pela pandemia da Covid-19, assim como ocorreu em outros países. Analisar a situação do ensino remoto, nesse contexto, possibilitou verificar, para além de desigualdades relacionadas às realidades materiais, outras, em analogia a estas, no universo virtual; ou seja, os indivíduos com aprendizagens defasadas também apresentaram maiores dificuldades nos meios digitais, tanto para o acesso, como para o uso das ferramentas. Isso evidenciou espaços de poderes e desigualdades no universo virtual, semelhantes ao do universo material. Levantamentos futuros poderão confirmar ou refutar as hipóteses de aumento das desigualdades. Relembra-se, no entanto, da necessidade de grande esforço coletivo, no sentido de evitar a evasão e elevadas taxas de reprovação, no ano letivo de 2020; assim como a necessidade de adequações aos currículos e programas para os próximos anos letivos.

Ademais, com a presente análise qualitativa, em documentos e falas de entrevistados, foi possível perceber uma sociedade dividida em crenças e posições políticas, que por vezes atrapalharam a construção de uma nova forma de ação social, e elaboração de políticas públicas. Em momentos de crise, faz-se ainda mais necessária a união de forças em prol de objetivos comuns, e nesse sentido o presente estudo demonstrou que o Brasil, com seus agentes, ainda tem muito a construir e amadurecer, ponderando lados e alinhando discurso, no sentido de práticas precisas, efetivas e solidárias.

O presente estudo pode contribuir na compreensão de como as disposições de habitus são híbridas, construídas a partir das experiências vividas, envolvendo afeto, e no contato com as estruturas materiais e também mentais de cada sujeito. Foi possível aferir novas formas de agir e pensar, relacionadas às maneiras de se ensinar e aprender os conteúdos formais da educação, assim como novas formas 
de se pensar a relação professor e estudante, e entre pares, numa perspectiva de mudanças, rupturas e construções de novas ações e comportamentos.

Os diversos contextos socializadores convidam, novamente, a repensar a educação para além dos muros escolares, numa perspectiva de uma educação promotora de experiências abrangentes e significativas, conectadas ao tempo presente, e colaborativa para o desenvolvimento científico e ético, que associem necessidades individuais e coletivas, com respeito e solidariedade.

\section{Notas}

1 Os sujeitos foram contatados via Google Classroom, e-mail e WhatsApp. Para os estudantes da Educação Básica perguntou-se: Você acredita que a utilização do Google Classroom e WhatsApp, durante este período de ensino remoto, mudou a forma de vocês estudarem e aprenderem? Será que isso irá trazer alguma consequência no jeito de vocês estudarem e aprenderem depois que as aulas voltarem a ser presenciais? Para os professores da Educação Básica perguntou-se: Vocês acreditam que a utilização do Google Classroom, durante este período de Ensino Remoto, impactará de alguma forma sua prática docente? Em caso afirmativo, de que forma? E para os estudantes da Pós-graduação se perguntou: As práticas de aulas remotas impactaram, de alguma maneira, a sua forma de estudar e de aprender? Em caso afirmativo, como?

2 Nomes Fictícios visando preservar a identidade dos respondentes. Quanto às siglas: (EB) se refere a estudantes da Educação Básica; (P) se refere a professores da Educação Básica; e (PG) se refere a estudantes da Pós-Graduação.

\section{Referências}

APP SINDICATO. Sindicato dos Trabalhadores em Educação Pública do Paraná. Manifesto por uma educação humanizadora e em defesa da vida: contra as políticas educacionais de produção de exclusão e desigualdades em tempo de pandemia de COVID-19. Curitiba, 2020. Disponível em: https://appsindicato.org.br. Acesso em: 15 jun. 2020.

BERGER, P. L.; LUCKMANN, T. A construção social da realidade. 36. ed. Petrópolis: Vozes, 2014.

BERTHELOT, Jean-Michel. Pour un bilan de la sociologie de l'éducation. In: COLLOQUE DE TOULOUSE, 1983. Anais [...]. Toulouse, 1983.

BOURDIEU, Pierre. Homo Academicus. Florianópolis: Ed. da UFSC, 2013.

BOURDIEU, Pierre. Meditações Pascalianas. Rio de Janeiro: Bertrand Brasil, 2001.

BOURDIEU, Pierre; CHARTIER, Roger. O sociólogo e o historiador. Belo Horizonte: Autêntica, 2012 .

BRASIL. Decreto-Lei n. ${ }^{\circ}$ 2.246-A, de 17 de outubro de 2007. Veda o uso de telefones celulares nas escolas públicas de todo o país. Câmera dos Deputados. Brasília, DF, 2009. Disponível em: https://www.camara.leg.br. Acesso em: 10 jul. 2020. 
BRASIL. Parecer CNE/CP №: 05/2020, de 28 de abril de 2020. Proposta de parecer sobre reorganização dos calendários escolares e realização de atividades pedagógicas não presenciais durante o período de pandemia da COVID-19. Ministério da Educação - Conselho Nacional de Educação. Brasília, DF, 2020a. Disponível em: http://portal.mec.gov.br. Acesso em: 10 jul. 2020.

BRASIL. Parecer CNE/CP №: 11/2020, de 7 de julho de 2020. Orientações Educacionais para a Realização de Aulas e Atividades Pedagógicas Presenciais e Não Presenciais no contexto da Pandemia. Ministério da Educação - Conselho Nacional de Educação. Brasília, DF, 2020b. Disponível em: http://portal.mec.gov.br. Acesso em: 10 jul. 2020.

BRASIL. Ministério da Saúde. Covid-19 no Brasil, painel interativo do Ministério da Saúde. 2021. Disponível em: https://susanalitico.saude.gov.br/extensions/COVID-19_html/COVID-19_ html.html. Acesso em: 09 abr. 2021.

BUENO, Paula Alexandra Reis; BUENO, Roberto Eduardo. A construção social do professor de música. Educar em Revista, Curitiba, v. 35, n. 73, p. 209-227, jan./fev. 2019. Disponível em: https://doi.org/10.1590/0104-4060.60146. Acesso em: 10 jun. 2020.

CAMPANHA Nacional pelo Direito à Educação. 8 motivos para não substituir a educação presencial pela educação a distância (EaD) durante a pandemia. São Paulo, 2020. Disponível em: https://campanha.org.br. Acesso em: 15 jun. 2020.

DUBAR, Claude. A socialização: construção das identidades sociais e profissionais. São Paulo: Martins Fontes, 2005.

DURKHEIM, Émile. Educação e Sociologia. Rio de Janeiro: Melhoramentos, 1978.

FUNDAÇÃO CARLOS CHAGAS. Educação escolar em tempos de pandemia na visão de prefessoras(es) da Educação Básica. São Paulo, 2020. Disponível em: www.fcc.org.br. Acesso em: 10 jul. 2020 .

LAHIRE, B. A fabricação social dos indivíduos: quadros, modalidades, tempos e efeitos de socialização. Revista Educação e Pesquisa, São Paulo, v. 41, n. especial, p. 1393-1404, dez. 2015. Disponível em: https://doi.org/10.1590/S1517-9702201508141651. Acesso em: 10 jun. 2020.

LAHIRE, B. A cultura dos indivíduos. Porto Alegre: Artmed, 2006.

MEAD, George Herbert. Espíritu, persona y sociedad. Buenos Aires: Paidós, 1968.

OPAS/OMS BRASIL. Organização Pan-Americana da Saúde e Organização Mundial da Saúde no Brasil. Disponível em: www.paho.org. Acesso em: 15 jun. 2020.

PARANÁ. Deliberação CEE/CP №: 01/2020, de 31 de março de 2020. Instituição de regime especial para o desenvolvimento das atividades escolares no âmbito do Sistema Estadual de Ensino do Paraná em decorrência da legislação específica sobre a pandemia causada pelo Novo Coronavírus - COVID-19 e outras providências. Conselho Estadual de Educação. Curitiba, PR, 2020. Disponível em: http://www.cee.pr.gov.br. Acesso em: 15 jun. 2020.

SEED/PR. Secretaria de Educação e Esporte do Paraná. Educação desenvolve EaD com foco no protagonismo dos professores. Curitiba, 2020. Disponível em: http://www.educacao.pr.gov.br. Acesso em: 20 jun. 2020.

SETTON, Maria da Graça Jacintho. Socialização e Individuação: a busca pelo reconhecimento e a escolha pela educação. São Paulo: Annablume, 2016. 
SETTON, Maria da Graça Jacintho. Teoria disposicionalista e habitus alimentar: elementos de orientação para análises acerca da incorporação de disposições culturais. In: SILVA, Fabiany Tavares; PEREIRA, Marcus Medeiros (org.). Observatório de cultura escolar: estudos e pesquisas sobre escola, currículo e cultura escolar. Campo Grande: UFMS, 2013. v. 1. p. 119-142.

SETTON, Maria da Graça Jacintho. Socialização e Cultura: ensaios teóricos. São Paulo: Annablume; Fapesp, 2012.

SETTON, Maria da Graça Jacintho; BOZZETTO, Adriana. Notas provisórias sobre a noção de socialização: uma leitura em periódicos da educação (1998-2018). Educação e Sociedade, Campinas, v. 41, 2020. Disponível em: https://doi.org/10.1590/es.227930. Acesso em: 10 jun. 2020.

SIMMEL, Georg. Filosofia do amor. São Paulo: Martins Fontes, 2001.

TODOS PELA EDUCAÇÃO. Nota técnica: Ensino à distância na educação básica frente à pandemia da COVID-19. 2020. Disponível em: www.todospelaeducacao.org.br. Acesso em: 15 jun. 2020 .

THOMASSIM, Luís Eduardo; HOFFMANN-HOROCHOVSKI, Marisete Teresinha. O que pensam crianças e familiares das aulas remotas: notas preliminares da pesquisa. In: UFPR LITORAL. Universidade Federal do Paraná Setor Litoral. Notas preliminares de pesquisa sobre aulas remotas. Matinhos, 2020. Disponível em: https://lugardecriancaufprlitoral.blogspot. com/2020/06/nota-de-pesquisa-aulas-remotas-jun2020.html. Acesso em: 15 jun. 2020.

UNIVERSIDADE FEDERAL DO PARANÁ. Resolução CEPE №: 59/2020, de 23 de junho de 2020. Regulamenta, em caráter excepcional, período especial para o desenvolvimento de atividades de ensino nos cursos de educação superior, profissional e tecnológica da UFPR, no contexto das medidas de enfrentamento da pandemia de COVID-19 no País. Conselho de Ensino Pesquisa e Extensão - CEPE. Curitiba, PR, 2020. Disponível em: www.ufpr.br. Acesso em: 15 jun. 2020.

WORLD HEALTH ORGANIZATION. Director-General's opening remarks at the media briefing on COVID-19. 2020. Disponível em: www.who.int. Acesso em: 15 jun. 2020. 